\title{
Cerebral embolism due to non-bacterial thrombotic endocarditis following pregnancy
}

\author{
J GEORGE,${ }^{*}$ JT LAMB,$\dagger$ DGF HARRIMAN $\ddagger$ \\ From the Departments of Neurology, ${ }^{*}$ Neuroradiology $\dagger$ and Neuropathology, $\ddagger$ Leeds General Infirmary, \\ Leeds, $U K$
}

SUMmARY A case is reported of cerebral embolism with two very unusual features. Two bilaterally symmetrical haemorrhagic infarcts occurred, due to non-bacterial thrombotic cardiac valvular vegetations precipitated by the puerperium in a previously healthy young woman.

Cerebrovascular accidents in association with childbirth are uncommon and were originally ascribed to cerebral thrombophlebitis. ${ }^{1}$ However Cross, Castro and Jennett reported thirty-one patients of whom twenty-five had arterial disease and it is now accepted that cerebrovascular accidents in pregnancy and the puerperium are as likely to be of arterial as of venous origin. ${ }^{2}$ In the patient we now report arterial occlusion occurred but was due to emboli from non-bacterial thrombotic endocarditis following pregnancy.

\section{Case report}

A previously healthy 25 -year-old woman suddenly developed a severe headache and increasing drowsiness, four days after delivery. Her thirty-four week pregnancy was normal apart from unexplained polyhydramnios and she had been discharged from the maternity unit following a normal spontaneous delivery. On admission she was deeply unconscious with bilateral extensor plantar responses. She was apyrexial and the blood pressure was $140 / 90 \mathrm{~mm} \mathrm{Hg}$. Heart sounds were normal and no murmurs were heard. Full blood count including platelet count was normal. The electrocardiogram and chest radiograph were normal. Computed tomography showed bilateral haemorrhagic lesions in the basal ganglia (fig, a). Shortly after admission her respiration deteriorated and she required artificial ventilation. She remained unconscious and died three days after admission. At necropsy numerous non-bacterial thrombotic vegetations were found on the mitral valve. The

Address for reprint requests: Dr J George, Dept. of Medicine for the Elderly, St. James's University Hospital, Leeds LS9 7TF, UK.

Received 15 July 1983. Accepted 6 August 1983 brain showed bilateral haemorrhagic infarcts centred on the external capsules (fig, b). Horizontal sections below the infarcts revealed small arteries containing fibrinous emboli similar in microscopical structure to the myocardial vegetations. No other infarcts were found and there was no evidence of an underlying carcinoma.

\section{Discussion}

Non-bacterial thrombotic endocarditis is characterised by sterile vegetations consisting mainly of fibrin without inflammatory cells and with no destruction of the underlying heart valve. It is easily distinguished histologically from infective endocarditis. Its aetiology is incompletely understood though it is associated with disturbances of coagulation mechanisms. ${ }^{3}$ Diagnosis during life is difficult as cardiological examination is often normal and there are no reliable laboratory tests. Echocardiography may help in making the diagnosis and successful treatment by prosthetic valve replacement has been reported. ${ }^{+}$

This type of thrombotic vegetations on heart valves is usually associated with malignant neoplasms but has been recoided in a wide variety of non-malignant conditions. ${ }^{5}$ It rarely occurs in otherwise healthy people and in this patient the cause may be associated with the increased clotting tendency present during pregnancy and the puerperium. ${ }^{6}$ As far as we are aware, non-bacterial thrombotic endocarditis has not previously been reported following pregnancy.

The clinical history and computed tomogram appearance in this patient suggested primary basal ganglia haemorrhages. Subsequent necropsy and histological study showed the lesions to be haemor- 

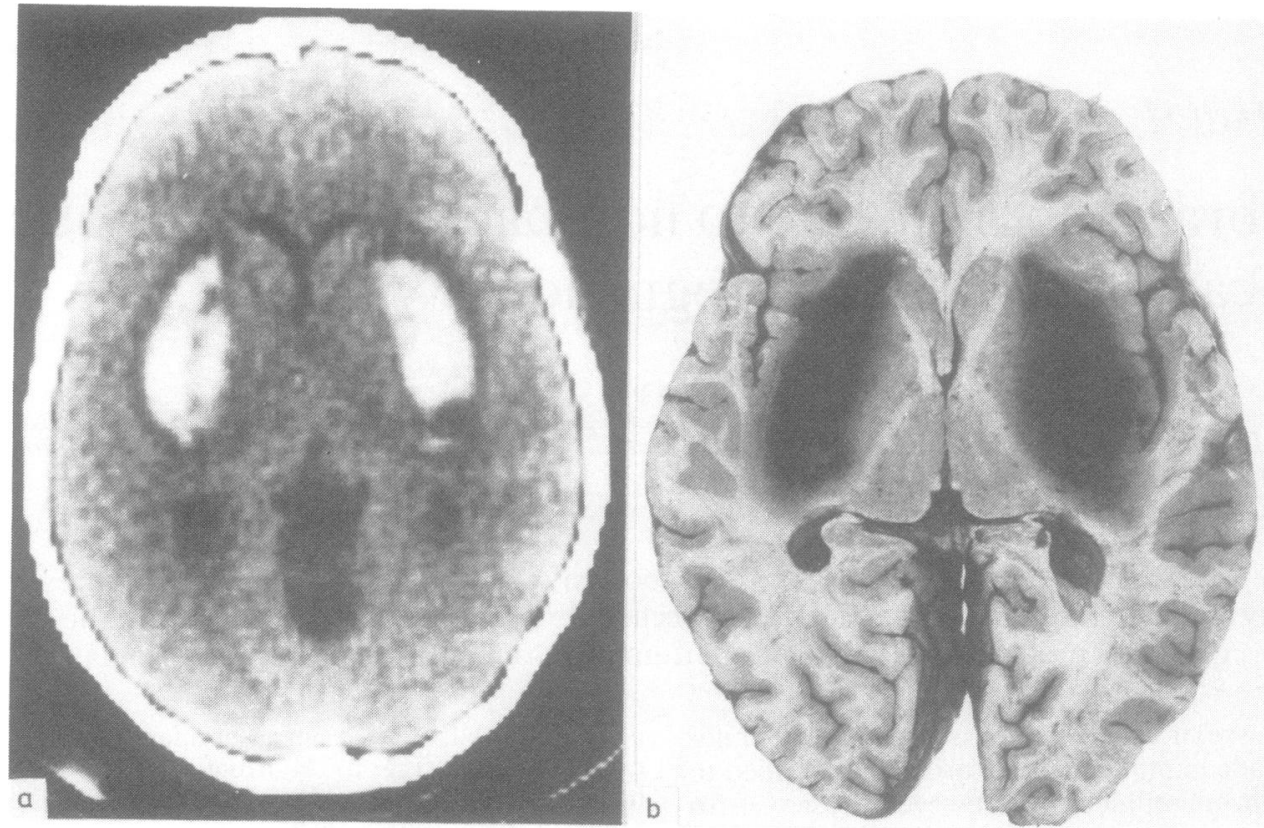

Fig Bilaterally symmetrical haemorrhagic infarcts in the external capsule and lentiform nuclei.

(a) non-enhanced CT scan, (b) horizontal section brain.

rhagic infarcts due to embolism. Haemorrhagic infarction secondary to non-bacterial thrombotic endocarditis is well recognised but the infarcts are usually multiple and asymmetrical. ${ }^{5}$ In this patient the simultaneous onset of such symmetrical lesions and the absence of infarcts elsewhere is remarkable.

Recognised causes of bilateral cerebral infarction causing coma include thrombosis of the vein of Galen in children ${ }^{7}$ and bilateral thalamic-subthalamic perforating artery occlusion. In the latter, bilateral symmetrical thalamic infarction is predisposed to by anatomical variations in which both perforating arteries arise close together or as a single trunk. ${ }^{x}$ However in our patient the position of the infarcts in the classical site for primary cerebral haemorrhages, lateral to the thalami, suggest that the emboli must have lodged in the lateral striate branches of both middle cerebral arteries including Charcot's "arteries of cerebral haemorrhage". The exact anatomical mechanism of this remains unclear.

The authors wish to thank Dr M Parsons and Dr JA Twomey for their help in preparing the manuscript and $\mathrm{Mr} \mathrm{AE}$ Wall for allowing us to present his patient.

\section{References}

' Carroll JD, Leak D, Lee HA. Cerebral thrombophlebitis in pregnancy and the puerperium. $Q \mathrm{~J}$ Med 1966;35:347-68.

${ }^{2}$ Cross JN, Castro PO, Jennett WB. Cerebral strokes associated with pregnancy and the puerperium. Br Med $J$ 1968;3:214-8.

${ }^{3}$ Anonymous. Non-bacterial thrombotic endocarditis. $\mathrm{Br}$ Med J 1978;1:197-8.

${ }^{4}$ Estevez CM, Corya BC. Serial echocardiographic abnormalities in non-bacterial thrombotic endocarditis of the mitral valve. Chest 1976;69:801-4.

${ }^{5}$ Biller J, Challa VR, Toole JF, Howard VJ. Non-bacterial thrombotic endocarditis. A neurologic perspective of clinicopathologic correlations of 99 patients. Arch Neurol 1982;39:95-8.

- Bonnar J, McNicol GP. Douglas AS. Coagulation and fibrinolytic mechanisms during and after normal childbirth. Br Med J 1970;2:200-3.

${ }^{7}$ Banker BQ. Cerebral vascular disease in infancy and childhood. 1. Occlusive vascular diseases. $J$ Neuropathol Exp Neurol 1961;20:127-40.

${ }^{*}$ Plum F, Posner JB. The Diagnosis of Stupor and Coma. Philadelphia: Davis, 1980:137-8. 